\title{
Platelet count and mean platelet volume are associated with not only bone, soft tissue, and lymph node metastases but also with malignant pleural effusion in lung cancer patients
}

\author{
M. OHUCHI*, S. INOUE, Y. OZAKI, K. UEDA \\ Department of general thoracic surgery, National Hospital Organization Higashi-Ohmi General Medical Center, 255 Gochi-cho, Higashi-Ohmi- \\ shi, Shiga 527-8505 Japan \\ ${ }^{*}$ Correspondence: ohuchi-masatsugu@shiga-hosp.jp
}

Received July 2, 2016 / Accepted September 12, 2016

\begin{abstract}
An increased platelet count is often observed in lung cancer patients. Whether and how the platelets affect cancer progression have yet to be established. The aim of the study was to investigate the involvement of the platelet count and mean platelet volume (MPV) in the prognosis and progression of lung cancer patients. This retrospective study included 146 patients with newly diagnosed primary lung cancer. The platelet count and MPV were measured before invasive diagnostic procedures and treatment. These platelet indices, overall survival of the patients, and tumor metastases for each organ were analyzed. On Kaplan-Meier survival analysis, the overall survivals of patients with platelet counts $\leq 244.0 \times 10^{9} / \mathrm{L}$ or MPV $>9.7 \mathrm{fL}$ were longer than those of patients with platelet counts $>244.0 \times 10^{9} / \mathrm{L}$ or MPV $\leq 9.7 \mathrm{fL}$. Cox regression analysis showed that poor performance status, increased platelet count, and increased C-reactive protein were independent prognostic factors. The platelet indices were associated with metastases to bone, soft tissue, and lymph node, in addition to malignant pleural effusion. Increased platelet count and decreased MPV were unfavorable prognostic factors for patients with lung cancer, and they were involved in bone, soft tissue, and lymph node metastases and malignant pleural effusion.
\end{abstract}

Key words: thrombocytosis, activated platelet, vascular endothelial growth factor, inflammation

Lung cancer is the most frequent cause of cancer death worldwide [1]. Despite recent improvement of diagnostic and therapeutic technologies, more than half of the patients diagnosed with lung cancer present with advanced disease, and the prognosis remains poor because distant metastases are common [2].

Thrombocytosis is often observed in patients with various malignant tumors including lung cancer [3]. Previous studies have reported that thrombocytosis is an independent predictor of poor prognosis in lung cancer patients [4-9]. The other platelet indices such as mean platelet volume (MPV), which can be measured simultaneously with platelet count from available routine blood examinations, were also associated with the prognosis of lung cancer patients [10-12]. Although various cut-off values of these platelet indices were used, and patients' background characteristics such as histological types and staging varied among these studies, it was obvious that an increased platelet count is one of the negative predictors for survival of lung cancer patients.
Recently, platelets have been shown to be involved in coagulation and inflammation, in addition to blood clotting, and activated platelets play an important role in cancer progression through diverse mechanisms [13]. The reports that thrombocytosis is a predictor of poor prognosis in lung cancer patients strongly suggest that platelets can facilitate cancer progression. However, whether and how the platelets affect the metastatic process of lung cancer have not been fully understood. The aim of the present study was to investigate the involvement of the platelet count and MPV in the prognosis and metastases of lung cancer.

\section{Patients and methods}

Patients. This retrospective study included 169 consecutive patients with lung cancer who were first-ever admitted to our department between January 2010 and December 2011. Patients with other current malignancies, recent 
surgery or trauma, a recent intervention for ischemic heart disease, and hematological disorders were excluded. Thus, data from 146 patients were finally analyzed after excluding 18 patients because they were lost to follow-up. The research protocol was approved by the ethics committee at our institution (28-4). All patients underwent chest and abdominal computed tomography (CT), brain magnetic resonance imaging, positron emission tomography-CT, and bone scintigraphy at the first presentation for evaluation of the clinical stage.

Patient evaluation. The clinical data were obtained from hospital records. Histological classification was performed according to WHO guidelines. The following clinical characteristics were retrieved from the available clinical records: age, sex, Eastern Cooperative Oncology Group (ECOG) performance status (PS), and smoking habit. Disease staging was based on the 7th edition of the tumor-node-metastasis (TNM) classification of malignant tumors as clinical stage or pathological stage. All lung cancer patients without small cell carcinoma or sufficient histological specimen undergo the examination of epidermal growth factor receptor (EGFR) mutation. Overall survival (OS) was defined as the time in weeks from definite diagnosis to death or the end of follow up (10 March, 2016).

Blood collection and laboratory analysis. All peripheral venous blood samples were collected from patients before invasive diagnostic procedures and treatments for lung cancer. A blood test was performed using a fully automated blood cell counting system from ethylenediamine tetra-acetic acid (EDTA) - anticoagulated blood samples in our clinical laboratory. Laboratory data including hemoglobin level, platelet counts, and MPV were collected.

Statistical analysis. Data were analyzed using R statistical software, version 3.1.1 (R Foundation for Statistical Computing, Vienna, Austria). Variables are expressed as means \pm standard deviation. Two-group unpaired continuous variables were compared using the t-test. Significant differences in quantitative variables between groups were analyzed using one-way analysis of variance (ANOVA) with a post hoc Dunnett test. Values with two-sided $p<0.05$ were considered significant. To assess the accuracy of using the platelet count or MPV as an indicator of survival, a receiver operator characteristic (ROC) curve was drawn. The ROC curve is a plot of sensitivity vs. 1-specificity. The area under the curve (AUC) was calculated from the ROC curve. The Kaplan-Meier method was used to calculate survival probability, and logrank tests were used to evaluate differences between groups. Overall survival was analyzed using Cox proportional hazards regression models. Factors initially considered in the univariate analysis that were associated with mortality $(\mathrm{P}<0.10)$ were included in the multivariate regression analysis using backward stepwise elimination. For the final model, hazard ratios (HRs), 95\% confidence intervals (CIs), parameter, and standard error were calculated for all significant predictors at the $\mathrm{P}<0.05$ level.

\section{Results}

Patient characteristics. Table 1 shows the main characteristics of the 146 patients (median age, $72.5 \mathrm{y}$; age range, 41-92 y). TNM stage varied as follows: Stage I, 46 patients; Stage II, 13 patients; Stage III, 35 patients; and Stage IV, 52 patients. Before invasive diagnostic procedures and treatments, the mean platelet count was $250.8 \pm 87.7 \times 10^{9} / \mathrm{L}$ and the mean MPV was $9.74 \pm 0.87 \mathrm{fL}$. Of the 146 patients, $24(16.4 \%)$ had malignant pleural effusions, and 39 (26.7\%) had distant organ metastases. There were no significant differences in the platelet count or MPV by EGFR mutation, sex, histological type, and PS.

Platelet indices and overall survival. By final follow-up, of the 146 patients, 45 had survived and 101 had died. The 5 -year overall survival rate was $30.6 \%$ and the median survival time (MST) was 595 days. Of the 101 non-survivors, 85 died of lung cancer.

The relationships between platelet indices and mortality were investigated first. These patients were divided into two groups: the 99 patients who had died within 5 years (nonsurvivors) and the other 47 surviving patients (survivors). The platelet count was significantly higher in non-survivors than in survivors, but MPV values were lower (Figure 1).

ROC curves were drawn to evaluate the accuracy of using platelet counts and MPV values as indicators of 5-years overall survival. The AUC was calculated as 0.694 (95\% CI: $0.610-0.778)$ for the platelet count and 0.656 (95\% CI: $0.561-0.751)$ for MPV. A platelet count of $244.0 \times 10^{9} / \mathrm{L}$ and an MPV of 9.70 were chosen as appropriate cut-off values to

Table 1. Characteristics of the patients.

\begin{tabular}{ll}
\hline Characteristics & $\mathrm{n}=146$ \\
\hline Sex (M/F) & $90 / 56$ \\
Median age, years (range) & $72.5(41-92)$ \\
ECOG PS $(0 / 1 / 2 / 3 / 4)$ & $91 / 27 / 15 / 7 / 6$ \\
Smoking habit & $110(75.3 \%)$ \\
Histological type (Ad/Sq/Sm/Others) & $80 / 43 / 14$ / 9 \\
Staging (IA/IB/IIA/IIB/IIIA/IIIB/IV) & $35 / 11 / 8 / 5 / 18 / 17$ / 52 \\
EGFR mutation positive & $24(16.4 \%)$ \\
Lymph nodes metastases (N0/N1/N2/N3) & $65 / 14 / 44 / 23$ \\
Distant metastases & $39(36.4 \%)$ \\
Metastatic organs & \\
$\quad$ Bone & $20(13.7 \%)$ \\
$\quad$ Lung & $14(9.6 \%)$ \\
$\quad$ Liver & $13(8.9 \%)$ \\
$\quad$ Brain & $10(6.8 \%)$ \\
$\quad$ Adrenal gland & $10(6.8 \%)$ \\
$\quad$ Soft tissue & $7(4.8 \%)$ \\
Malignant pleural effusion & $24(16.4 \%)$ \\
Obstructive pneumonia & $22(15.1 \%)$ \\
\hline
\end{tabular}

ECOG: Eastern Cooperative Oncology Group, PS: Performance status, Ad: Adenocarcinoma, Sq: Squamous cell carcinoma, Sm: Small cell carcinoma, EGFR: epidermal growth factor receptor. 
A

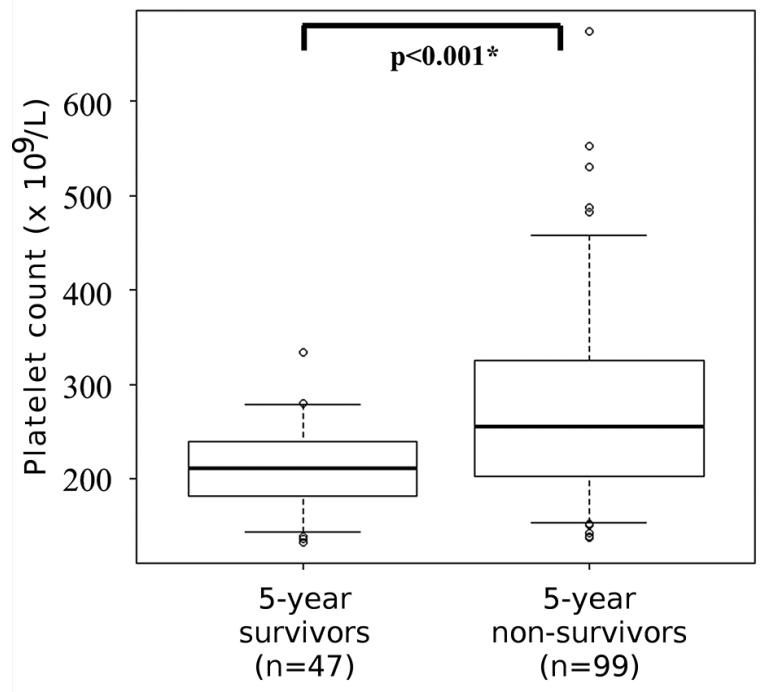

$21.07 \pm 4.33$

$27.31 \pm 9.94$
B

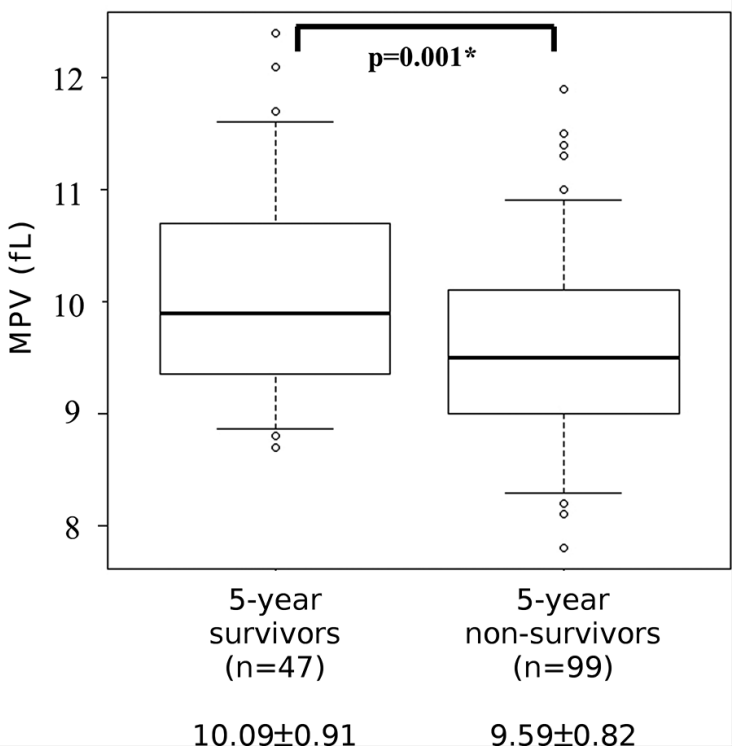

Figure 1. Platelet count (A) and MPV (B) in 5-year survivors and non-survivors. MPV: Mean platelet volume

predict 5-year mortality with sensitivities of $55.6 \%$ and $65.7 \%$, and specificities of $78.7 \%$ and $61.7 \%$, respectively.

Of these patients, 81 patients had platelet counts $\leq 244.0$ $\times 10^{9} / \mathrm{L}$, and their MST was 1,523 days. For the remaining 65 patients whose platelet counts were $>244.0 \times 10^{9} / \mathrm{L}$, the MST was 405 days. The Kaplan-Meier survival analysis showed that the OS of the patients whose platelet count was $>244.0 \times 10^{9} / \mathrm{L}$ was significantly lower than that of the patients whose platelet count was $\leq 244.0 \times 10^{9} / \mathrm{L}(\log$ rank test, $\mathrm{P}<0.001$, Figure $2 \mathrm{~A}$ ). The $\mathrm{OS}$ of patients whose MPV was $\leq 9.7 \mathrm{fL}$ was also significantly lower than that of patients whose MPV was > $9.7 \mathrm{fL}$ (MST: 408 days vs. 946 days, $\mathrm{P}=0.005$, Figure 2B).

Table 2. Univariate analysis of prognostic factors for 5-year overall survival.

\begin{tabular}{lcc}
\hline Variables & HR $(95 \% \mathrm{CI})$ & P value \\
\hline Sex $(\mathrm{M} / \mathrm{F})$ & $1.12(0.75-1.67)$ & 0.594 \\
Median age, years & $1.04(1.02-1.06)$ & $0.001^{*}$ \\
ECOG PS $(0 / 1 / 2 / 3 / 4)$ & $1.79(1.51-2.12)$ & $<0.001^{*}$ \\
Smoking habit & $1.97(1.18-3.28)$ & $0.010^{*}$ \\
CRP $(\mathrm{mg} / \mathrm{dl})$ & $1.13(1.09-1.17)$ & $<0.001^{*}$ \\
Platelet count $\left(\leq\right.$ or $\left.>244.0 \times 10^{9} / \mathrm{L}\right)$ & $2.29(1.54-3.41)$ & $<0.001^{*}$ \\
Hemoglobin $(\mathrm{g} / \mathrm{dl})$ & $0.77(0.68-0.86)$ & $<0.001^{*}$ \\
EGFR mutation & $0.34(0.17-0.48)$ & $0.002^{*}$ \\
CEA $(\mathrm{ng} / \mathrm{ml})$ & $1.00(0.99-1.00)$ & 0.200 \\
Cyfra $(\mathrm{ng} / \mathrm{ml})$ & $1.03(1.02-1.04)$ & $<0.001^{*}$ \\
\hline
\end{tabular}

HR: Hazard ratio, ECOG: Eastern Cooperative Oncology Group, PS: Performance status, CRP: C-reactive protein, EGFR: epidermal growth factor receptor, CEA: carcinoembryonic antigen, Cyfra: Cytokeratin 19 fragment
The associations between mortality and sex, age, smoking habit, histological type, PS, C-reactive protein, platelet count ( $\leq$ or $\left.>244.0 \times 10^{9} / \mathrm{L}\right)$, hemoglobin level, EGFR mutation, carcinoembryonic antigen (CEA), and cytokeratin 19 fragment (Cyfra) were evaluated.

On univariate regression analysis, smoking habit, EGFR mutation, higher age, PS, CRP, platelet count, Cyfta, and lower level of hemoglobin were significant (Table 2). These eight variables $(\mathrm{P}<0.10$ on univariate analysis) were entered into a multivariate regression analysis with mortality as the independent variable. The variables in the final model that could better predict the patient survival rate are shown in Table 3 .

Platelet indices and metastases. Furthermore, the relationships between platelet indices and lymph node, pleural, and distant metastases were investigated. The platelet counts of patients with bone, soft tissue, or lymph node metastases or malignant pleural effusion were significantly higher than those of patients without them (Table 4). Although the MPV of patients with metastasis, excluding those with malignant effusion, was significantly lower than that of patients without them, the difference in MPV between patients with and without malignant pleural effusion was not significant. Further multiple comparisons showed that the platelet count of N0 was significantly lower than that of $\mathrm{N} 1(\mathrm{P}=0.036), \mathrm{N} 2(\mathrm{P}=0.012)$, and N3 $(\mathrm{P}<0.001)$.

\section{Discussion}

In the present study, both higher platelet count and lower MPV were associated with a poor prognosis in lung cancer 
A

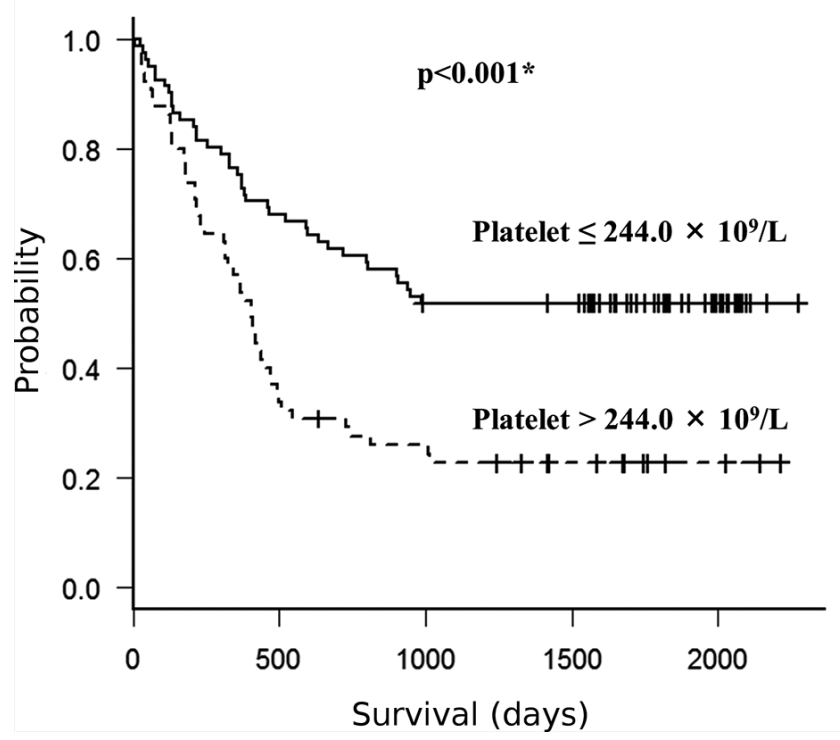

B

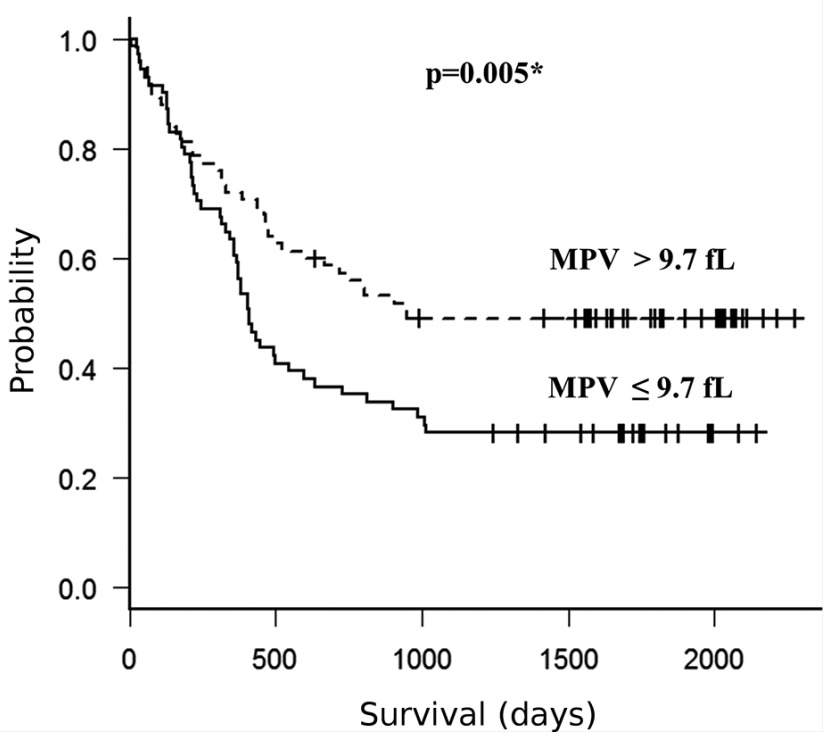

Figure 2. Kaplan-Meier curves for overall survival of the patients by platelet count (A) or MPV (B). MPV: Mean platelet volume

patients, and the platelet count was also an independent predictor of OS. Moreover, an increased platelet count was associated with bone, soft tissue, and lymph node metastases and malignant pleural effusion. In contrast, decreased MPV was associated with metastases, but not malignant pleural effusion. This is the first report to show that both the platelet count and MPV were involved in bone, soft tissue, and lymph node metastases and malignant pleural effusion in lung cancer patients.

Although there are some reports that demonstrated an association between an increased platelet count and lower survival in lung cancer patients, the cut-off value for an increased platelet count was set differently among the studies $[4-8,14]$. Most studies used a platelet count of $300-400 \times 10^{9} / \mathrm{L}$ as the cut-off. In contrast, in the present study, there was a significant difference in OS using a lower cut-off of the platelet count than in previous studies. This suggests that only a slightly increased platelet count, not prominent thrombocytosis, is associated with progression of lung cancer.

There are some possible mechanisms to explain how platelets are associated with a poor outcome in lung cancer patients. The first step of cancer progression is that cancer cells activate platelets by some factors that originate from cancer cells and platelets such as tissue factor, podoplanin, Pselectin, and glycoprotein Ib/IX/V [15-18]. Second, activated platelets interact with cancer cells leading to the formation of platelet- cancer cells that can evade shear stress in blood flow and immune surveillance and, furthermore, enhance tumor metastasis $[19,20]$. Third, platelet aggregation with cancer cells promotes microcirculatory adhesion to endothelial cells and colonization of cancer cells [21]. The release of platelet granules from activated platelets has an important role in

Table 3. The variables in the final model that could better predict the patient 5 -year survival rate by multivariate analysis.

\begin{tabular}{lcccccc}
\hline Variables & Difference & $\beta$ & HR $(95 \% \mathrm{CI})$ & SE $(\beta)$ & $\mathrm{z}$ \\
\hline Median age, years & 1 year & 0.012 & $1.01(0.98-1.05)$ & 0.017 & 0.69 & 0.490 \\
ECOG PS (0/1/2/3/4) & & 0.502 & $1.65(1.30-2.11)$ & 0.124 & 4.05 & $<0.001^{*}$ \\
Smoking habit & $0:$ no, $1:$ yes & 0.278 & $1.32(0.67-2.60)$ & 0.346 & 0.81 & 0.421 \\
CRP (mg/dl) & $0.1 \mathrm{mg} / \mathrm{dl}$ & 0.063 & $1.07(1.02-1.12)$ & 0.025 & 2.58 & $0.010^{*}$ \\
Platelet count & $0: \leq, \mathrm{l}:>$ & 0.630 & $1.88(1.13-3.13)$ & 0.261 & 2.42 & $0.016^{*}$ \\
Hemoglobin (g/dl) & $244.0 \times 10^{9} / \mathrm{L}$ & & $0.92(0.78-1.08)$ & 0.082 & -1.02 & 0.308 \\
EGFR mutation & $0.1 \mathrm{~g} / \mathrm{dl}$ & -0.083 & $0.63(0.27-1.46)$ & 0.432 & -1.08 & 0.278 \\
Cyfra (ng/ml) & $0:(-), 1:(+)$ & -0.468 & $1.01(1.00-1.03)$ & 0.007 & 1.54 & 0.123 \\
\hline
\end{tabular}

HR: Hazard ratio, SE: Standard error, ECOG: Eastern Cooperative Oncology Group, PS: Performance status, CRP: C-reactive protein, EGFR: epidermal growth factor receptor, Cyfra: Cytokeratin 19 fragment 
Table 4. The associations between platelet indices and metastases to each organ.

\begin{tabular}{|c|c|c|c|}
\hline & $\mathrm{n}$ & PLTS & MPV \\
\hline Distant metastases & & $\mathrm{P}=0.039^{*}$ & $\mathrm{P}=0.009^{*}$ \\
\hline metastases $(+)$ & 39 & $278.4 \pm 114.2$ & $9.44 \pm 0.84$ \\
\hline metastases(-) & 107 & $243.7 \pm 78.2$ & $9.86 \pm 0.87$ \\
\hline Adrenal gland & & $\mathrm{P}=0.617$ & $\mathrm{P}=0.820$ \\
\hline metastasis $(+)$ & 10 & $266.8 \pm 78.9$ & $9.81 \pm 0.97$ \\
\hline metastasis(-) & 136 & $252.0 \pm 91.1$ & $9.74 \pm 0.88$ \\
\hline Bone & & $\mathrm{P}=0.021^{*}$ & $\mathrm{P}=0.010^{*}$ \\
\hline metastasis $(+)$ & 20 & $295.9 \pm 130.6$ & $9.28 \pm 0.80$ \\
\hline metastasis(-) & 126 & $246.2 \pm 80.6$ & $9.82 \pm 0.87$ \\
\hline Brain & & $\mathrm{P}=0.324$ & $\mathrm{P}=0.397$ \\
\hline metastasis $(+)$ & 10 & $280.2 \pm 122.1$ & $9.52 \pm 0.36$ \\
\hline metastasis(-) & 136 & $251.0 \pm 87.6$ & $9.77 \pm 0.91$ \\
\hline Lung & & $\mathrm{P}=0.889$ & $\mathrm{P}=0.904$ \\
\hline metastasis $(+)$ & 14 & $256.2 \pm 79.3$ & $9.75 \pm 0.88$ \\
\hline metastasis(-) & 132 & $252.6 \pm 91.5$ & $9.72 \pm 0.92$ \\
\hline Liver & & $\mathrm{P}=0.156$ & $\mathrm{P}=0.369$ \\
\hline metastasis $(+)$ & 13 & $286.9 \pm 125.7$ & $9.54 \pm 0.76$ \\
\hline metastasis(-) & 133 & $249.7 \pm 85.8$ & $9.77 \pm 0.89$ \\
\hline Soft tissue & & $\mathrm{P}<0.001^{*}$ & $\mathrm{P}=0.011^{*}$ \\
\hline metastasis $(+)$ & 7 & $378.9 \pm 89.1$ & $8.93 \pm 0.88$ \\
\hline metastasis(-) & 139 & $246.6 \pm 85.7$ & $9.79 \pm 0.86$ \\
\hline Lymph node & & $\mathrm{P}<0.001^{*}$ & $\mathrm{P}=0.030^{*}$ \\
\hline No & 65 & $218.5 \pm 48.8$ & $9.98 \pm 0.91$ \\
\hline N1 & 14 & $281.4 \pm 119.6$ & $9.77 \pm 0.95$ \\
\hline N2 & 44 & $266.6 \pm 91.2$ & $9.53 \pm 0.73$ \\
\hline \multirow[t]{2}{*}{$\mathrm{N} 3$} & 23 & $307.1 \pm 120.4$ & $9.50 \pm 0.89$ \\
\hline & & $\mathrm{P}=0.022^{*}$ & $\mathrm{P}=0.711$ \\
\hline Malignant pleural effusion(+) & 24 & $291.3 \pm 113.7$ & $9.69 \pm 0.84$ \\
\hline Malignant pleural effusion(-) & 122 & $245.4 \pm 83.2$ & $9.76 \pm 0.89$ \\
\hline
\end{tabular}

PLTS: Platelet count, MPV: Mean platelet volume

this process [22]. Finally, activated platelets release vascular endothelial growth factor (VEGF), epidermal growth factor (EGF), platelet-derived growth factor (PDGF), and a number of other cytokines, which stimulate proliferation of cancer cells and promote angiogenesis [22]. In addition, Labelle and colleagues reported that transforming growth factor- $\beta$ (TGF- $\beta$ ) released from platelets induces epithelial-mesenchymal transition and promotes metastasis [23].

The results of the present study were in agreement with the previous studies showing that thrombocytosis was associated with bone and lymph node metastases [9, 14]. Platelets and their expression of podoplanin have an important role in the embryologic development of lymphatic vessels [24, 25]. Podoplanin is regarded as a factor promoting metastasis via platelet aggregation [26]. Furthermore, lymphangiogenic growth factors such as VEGF, PDGF, and basic fibroblastic growth factor (bFGF), which are synthesized by platelets, stimulate the development of lymphatic vessels via different pathways [27]. Moreover, Kerr and colleagues suggested that proteins released from platelets were involved in bone metastasis by stimulating proliferation of osteoblasts and the differentiation of osteoclast-like cells [28]. Although the precise mechanisms by which platelets are involved in bone and lymph node metastases remain unclear, it is certain that platelets are strongly associated with these metastases.

Previous studies demonstrated that a decreased MPV was significantly associated with inferior OS in patients with advanced lung cancer $[10,11]$. In fact, an increased platelet count and a decreased MPV were demonstrated in patients with lymph node and/or bone metastasis in the present study.

In contrast, there was dissociation between platelet count and MPV only in patients with a malignant effusion in the present study. The meaning of this dissociation should be considered. Angiogenesis, increased permeability of the pleural vasculature, and inflammation are considered to be involved in the pathogenesis of malignant pleural fluid accumulation $[29,30]$. It is well known that there is an inverse relationship between the platelet count and the MPV under physiological conditions, because circulating platelets tend to maintain hemostasis by preserving a constant platelet volume [31]. Conversely, Gasparyan and colleagues suggested that the size of circulating platelets depends on the intensity of systemic inflammation, with contrasting features of MPV in high- and low- grade inflammatory disorders [32]. Namely, the size seems to depend on the intensity of inflammation. They considered that low-grade inflammatory conditions are associated with circulation of predominantly larger platelets. Several studies have also presented data that allude to a correlation between higher MPV values and active inflammatory disease $[33,34]$. Larger platelets are more reactive than smaller ones as they can more easily release a large variety of chemical mediators in response to stimuli [35]. Thus, MPV is readily used as an early marker of platelet activation [36]. By the present results, the fact that the MPV level was relatively higher than the platelet count in malignant pleural effusion might be associated with low-grade inflammation in the pleural space.

In malignant pleural effusion, VEGF plays an essential role. Previous studies have shown that VEGF levels in pleural effusions are significantly higher in malignant pleural effusions than in benign pleural effusions [37-39]. VEGF is released from platelets and not only induces the formation of new blood vessels, but it also increases vascular permeability [40-42]. In addition, VEGF levels were correlated with several markers of increased vascular permeability and pleural inflammation [43-45]. It was reported that the level of VEGF released from a single activated platelet was strongly correlated with MPV under inflammation [46]. In other words, newly produced platelets, which have a large MPV, might contain more VEGF in their cytoplasm than mature platelets. These activated large platelets are associated with progression of malignant pleural effusion in the presence of inflammation in the pleural space 
through VEGF. Meanwhile, it was suggested that bevacizumab, a recombinant humanized monoclonal antibody to VEGF, was effective for the management of pleural effusions in lung cancer [47]. Mutlu et al. reported that the administration of bevacizumab in patients with metastatic colon cancer significantly decreased MPV levels [48]. Therefore, the dissociation between the platelet count and MPV in the present patients with malignant pleural effusion was supported by these findings and considerations.

Several limitations of the present study should be mentioned. The present study was a retrospective study, and there was insufficient information about treatment strategies for lung cancer, which may lead to differences in the survival rate. The population of patients in this study was heterogeneous. Because the platelet count and prognosis classified by staging were not significantly different between non-small cell carcinoma patients and small cell carcinoma patients, patients of both histological types were included in the study. However, the mechanisms associated with metastasis of these two types may be different. Although EGFR mutation is generally the most obvious predictor of survival once the patient took EGFR-tyrosine kinase inhibitor [49], EGFR mutation was not a predictor for 5-year survival on multiple regression analysis in this study. The reason was that the examination of EGFR mutation was undergone for all non-small cell lung cancer patients including early stage operable patients in our department. Furthermore, there are factors that affect the standardization of MPV measurement: blood sampling method, amount of anticoagulant in the blood collection tube, the duration between blood sampling and examination, and the device used for the examination [50]. Finally, the normal ranges of platelet counts are different among regions due to ethnicity and measurement methods, and these must be addressed. The problems of MPV measurement and regional differences in platelet counts might not need to be considered, because all samples were collected from Japanese persons, and platelet indices were measured by the same blood sampling method and blood counting system in a single institute.

In conclusion, in the present study, an increased platelet count and a decreased MPV were unfavorable prognostic factors for patients with lung cancer, and there was an association between platelet indices and not only bone, soft tissue, and lymph node metastases, but also malignant pleural effusion. Further larger prospective studies with patients subdivided by histological types or staging should be conducted to clarify the findings of this study.

\section{References}

[1] SIEGEL R, NAISHADHAM D, JEMAL A. Cancer statistics, 2012. CA Cancer J Clin 2012; 62: 10-29. https:/doi. org/10.3322/caac. 20138

[2] ZHU HJ, OGAWA M, MAGATA Y, HIRATA M, OHMOMO $\mathrm{Y}$ et al. Relationship between uptake of a radioiodinated quinazoline derivative and radiosensitivity in non-small cell lung cancer. Am J Nucl Med Mol Imaging 2014; 4: 293-302.

[3] SIERKO E, WOJTUKIEWICZ MZ. Platelets and angiogenesis in malignancy. Semin Thromb Hemost 2004; 30: 95-108. https:/doi.org/10.1055/s-2004-822974

[4] AOE K, HIRAKI A, UEOKA H, KIURA K, TABATA M et al. Thrombocytosis as a useful prognostic indicator in patients with lung cancer. Respiration 2004; 71: 170-173. https:/doi. org/10.1159/000076679

[5] GONZALEZ BARCALA FJ, GARCIA PRIM JM, MOLDES RODRIGUEZ M, ALVAREZ FERNANDEZ J, REY REY MJ et al. Platelet count: association with prognosis in lung cancer. Med Oncol 2010; 27: 357-362. https:/doi.org/10.1007/s12032$\underline{\text { 009-9217-9 }}$

[6] MARAZ A, FURAK J, VARGA Z, KAHAN Z, TISZLAVICZ $L$ et al. Thrombocytosis has a negative prognostic value in lung cancer. Anticancer Res 2013; 33: 1725-1729.

[7] KIM KH, PARK TY, LEE JY, LEE SM, YIM JJ et al. Prognostic significance of initial platelet counts and fibrinogen level in advanced non-small cell lung cancer. J Korean Med Sci 2014; 29: 507-511. https:/doi.org/10.3346/jkms.2014.29.4.507

[8] JI Y, SHENG L, DU X, QIU G, SU D. Elevated platelet count is a strong predictor of poor prognosis in stage I non-small cell lung cancer patients. Platelets 2015; 26: 138-142. https:/ doi.org/10.3109/09537104.2014.888547

[9] ZHANG W, YU C, HUANG B, ZHOU FL, HUANG HD et al. Correlation between bone metastasis and thrombocytosis in pulmonary adenocarcinoma patients. Oncol Lett 2015; 9: 762-768.

[10] INAGAKI N, KIBATA K, TAMAKI T, SHIMIZU T, NOMURA S. Prognostic impact of the mean platelet volume/platelet count ratio in terms of survival in advanced non-small cell lung cancer. Lung Cancer 2014; 83: 97-101. https:/doi.org/10.1016/j. lungcan.2013.08.020

[11] KUMAGAI S, TOKUNO J, UEDA Y, MARUMO S, SHOJI $\mathrm{T}$ et al. Prognostic significance of preoperative mean platelet volume in resected non-small-cell lung cancer. Mol Clin Oncol 2015; 3: 197-201.

[12] ONCEL M, KIYICI A, ONCEL M, SUNAM GS, SAHIN E et al. Evaluation of Platelet Indices in Lung Cancer Patients. Asian Pac J Cancer Prev 2015; 16: 7599-7602. https:/doi. org/10.7314/APJCP.2015.16.17.7599

[13] GASIC GJ, GASIC TB, STEWART CC. Antimetastatic effects associated with platelet reduction. Proc Natl Acad Sci U S A 1968; 61: 46-52. https:/doi.org/10.1073/pnas.61.1.46

[14] LIU HB, GU XL, MA XQ, LV TF, WU Y et al. Preoperative platelet count in predicting lymph node metastasis and prognosis in patients with non-small cell lung cancer. Neoplasma 2013; 60: 203-208. https:/doi.org/10.4149/neo 2013027

[15] KITAGAWA H, YAMAMOTO N, YAMAMOTO K, TANOUE $\mathrm{K}$, KOSAKI G et al. Involvement of platelet membrane glycoprotein Ib and glycoprotein IIb/IIIa complex in thrombindependent and -independent platelet aggregations induced by tumor cells. Cancer Res 1989; 49: 537-541.

[16] MISHIMA K, KATO Y, KANEKO MK, NISHIKAWA R, HIROSE $\mathrm{T}$ et al. Increased expression of podoplanin in malignant astrocytic tumors as a novel molecular marker of malignant 
progression. Acta Neuropathol 2006; 111: 483-488. https:/ doi.org/10.1007/s00401-006-0063-y

[17] JAIN S, ZUKA M, LIU J, RUSSELL S, DENT J et al. Platelet glycoprotein Ib alpha supports experimental lung metastasis. Proc Natl Acad Sci U S A 2007; 104: 9024-9028. https:/doi. org/10.1073/pnas.0700625104

[18] MILSOM C, RAK J. Tissue factor and cancer. Pathophysiol Haemost Thromb 2008; 36: 160-176. https:/doi. org/10.1159/000175154

[19] NIESWANDT B, HAFNER M, ECHTENACHER B, MANNEL DN. Lysis of tumor cells by natural killer cells in mice is impeded by platelets. Cancer Res 1999; 59: 1295-1300.

[20] EGAN K, COOKE N, KENNY D. Living in shear: platelets protect cancer cells from shear induced damage. Clin Exp Metastasis 2014; 31: 697-704. https:/doi.org/10.1007/s10585014-9660-7

[21] JURASZ P, ALONSO-ESCOLANO D, RADOMSKI MW. Platelet--cancer interactions: mechanisms and pharmacology of tumour cell-induced platelet aggregation. Br J Pharmacol 2004; 143: 819-826. https:/doi.org/10.1038/sj.bjp.0706013

[22] MAMMADOVA-BACH E, MANGIN P, LANZA F, GACHET C. Platelets in cancer. From basic research to therapeutic implications. Hamostaseologie 2015; 35: 325-336. https:/doi. org/10.5482/hamo-14-11-0065

[23] LABELLE M, BEGUM S, HYNES RO. Direct signaling between platelets and cancer cells induces an epithelial-mesenchymal-like transition and promotes metastasis. Cancer Cell 2011; 20: 576-590. https:/doi.org/10.1016/j.ccr.2011.09.009

[24] SCHACHT V, RAMIREZ MI, HONG YK, HIRAKAWA S, FENG D et al. T1alpha/podoplanin deficiency disrupts normal lymphatic vasculature formation and causes lymphedema. EMBO J 2003; 22: 3546-3556. https:/doi.org/10.1093/ emboj/cdg342

[25] MAHTAB EA, WIJFFELS MC, VAN DEN AKKER NM, HAHURIJ ND, LIE-VENEMA $H$ et al. Cardiac malformations and myocardial abnormalities in podoplanin knockout mouse embryos: Correlation with abnormal epicardial development. Dev Dyn 2008; 237: 847-857. https:/doi.org/10.1002/ dvdy. 21463

[26] KATO Y, FUJITA N, KUNITA A, SATO S, KANEKO M et al. Molecular identification of Aggrus/T1alpha as a platelet aggregation-inducing factor expressed in colorectal tumors. J Biol Chem 2003; 278: 51599-51605. https:/doi.org/10.1074/ jbc.M309935200

[27] NAKAYA H, KAWASHIRI S, TANAKA A, NOGUCHI N, KATO $\mathrm{K}$ et al. Influences of angiogenesis and lymphangiogenesis on cancerous invasion in experimentally induced tongue carcinoma. J Oral Pathol Med 2005; 34: 87-92. https:/ doi.org/10.1111/j.1600-0714.2004.00279.x

[28] KERR BA, MCCABE NP, FENG W, BYZOVA TV. Platelets govern pre-metastatic tumor communication to bone. Oncogene 2013; 32: 4319-4324. https:/doi.org/10.1038/ onc.2012.447

[29] WEST SD, DAVIES RJ, LEE YC. Pleurodesis for malignant pleural effusions: current controversies and variations in practices. Curr Opin Pulm Med 2004; 10: 305-310. https:/doi. org/10.1097/01.mcp.0000129756.87090.55
[30] STATHOPOULOS GT, PSALLIDAS I, MOUSTAKI A, MOSCHOS C, KOLLINTZA A et al. A central role for tumorderived monocyte chemoattractant protein-1 in malignant pleural effusion. J Natl Cancer Inst 2008; 100: 1464-1476. https:/doi.org/10.1093/jnci/djn325

[31] THOMPSON CB. From precursor to product: how do megakaryocytes produce platelets? Prog Clin Biol Res 1986; 215: 361-371.

[32] GASPARYAN AY, AYVAZYAN L, MIKHAILIDIS DP, KITAS GD. Mean platelet volume: a link between thrombosis and inflammation? Curr Pharm Des 2011; 17: 47-58. https:/doi. org/10.2174/138161211795049804

[33] MAGEN E, MISHAL J, ZELDIN Y, FELDMAN V, KIDON M et al. Increased mean platelet volume and C-reactive protein levels in patients with chronic urticaria with a positive autologous serum skin test. Am J Med Sci 2010; 339: 504-508. https:/doi.org/10.1097/MAJ.0b013e3181db6ed5

[34] YAZICI S, YAZICI M, ERER B, ERER B, CALIK Y et al. The platelet functions in patients with ankylosing spondylitis: anti-TNF-alpha therapy decreases the mean platelet volume and platelet mass. Platelets 2010; 21: 126-131. https:/doi. org/10.3109/09537100903470306

[35] THOMPSON CB, JAKUBOWSKI JA, QUINN PG, DEYKIN D, VALERI CR. Platelet size and age determine platelet function independently. Blood 1984; 63: 1372-1375.

[36] THOMPSON CB, JAKUBOWSKI JA. The pathophysiology and clinical relevance of platelet heterogeneity. Blood 1988; 72: $1-8$.

[37] ISHIMOTO O, SAIJO Y, NARUMI K, KIMURA Y, EBINA $\mathrm{M}$ et al. High level of vascular endothelial growth factor in hemorrhagic pleural effusion of cancer. Oncology 2002; 63: 70-75. https:/doi.org/10.1159/000065723

[38] GROVE CS, LEE YC. Vascular endothelial growth factor: the key mediator in pleural effusion formation. Curr Opin Pulm Med 2002; 8: 294-301. https:/doi.org/10.1097/00063198200207000-00009

[39] HAMED EA, EL-NOWEIHI AM, MOHAMED AZ, MAHMOUD A. Vasoactive mediators (VEGF and TNF-alpha) in patients with malignant and tuberculous pleural effusions. Respirology 2004; 9: 81-86. https:/doi.org/10.1111/j.14401843.2003.00529.x

[40] HOSHINO M, TAKAHASHI M, AOIKE N. Expression of vascular endothelial growth factor, basic fibroblast growth factor, and angiogenin immunoreactivity in asthmatic airways and its relationship to angiogenesis. J Allergy Clin Immunol 2001; 107: 295-301. https:/doi.org/10.1067/ mai.2001.111928

[41] ANTONY VB. Immunological mechanisms in pleural disease. Eur Respir J 2003; 21: 539-544. https:/doi.org/10.118 3/09031936.03.00403902

[42] GOEL HL, MERCURIO AM. VEGF targets the tumour cell. Nat Rev Cancer 2013; 13: 871-882. https:/doi.org/10.1038/ $\underline{\text { nrc3627 }}$

[43] KALOMENIDIS I, KOLLINTZA A, SIGALA I, PAPAPETROPOULOS A, PAPIRIS S et al. Angiopoietin-2 levels are elevated in exudative pleural effusions. Chest 2006; 129: 1259-1266. https:/doi.org/10.1378/chest.129.5.1259 
[44] ECONOMIDOU F, ANTONIOU KM, TZANAKIS N, SFIRIDAKI K, SIAFAKAS NM et al. Angiogenic molecule Tie-2 and VEGF in the pathogenesis of pleural effusions. Respir Med 2008; 102: 774-779. https:/doi.org/10.1016/j. rmed.2007.10.021

[45] DUYSINX BC, CORHAY JL, HUBIN L, NGUYEN D, HENKET M, et al. Diagnostic value of interleukine-6, transforming growth factor-beta 1 and vascular endothelial growth factor in malignant pleural effusions. Respir Med 2008; 102: 1708-1714. https:/doi.org/10.1016/j. rmed.2008.07.008

[46] UENO K, NOMURA Y, HASHIGUCHI T, MASUDA K, MORITA Y, et al. Platelet vascular endothelial growth factor is a useful predictor for prognosis in Kawasaki syndrome. Br J Haematol 2010; 148: 285-292. https:/doi.org/10.1111/j.13652141.2009.07922.x

[47] KITAMURA K, KUBOTA K, ANDO M, TAKAHASHI S, NISHIJIMA $\mathrm{N}$ et al. Bevacizumab plus chemotherapy for advanced non-squamous non-small-cell lung cancer with malignant pleural effusion. Cancer Chemother Pharmacol 2013; 71: 457-461. https:/doi.org/10.1007/s00280-012-2026-4

[48] MUTLU H, BERK V, KARACA H, ERDEN A, ASLAN T et al. Treatment regimen with bevacizumab decreases mean platelet volume in patients with metastatic colon cancer. Clin Appl Thromb Hemost 2012; 18: 546-548. https:/doi. org/10.1177/1076029611430958

[49] MITSUDOMI T, MORITA S, YATABE Y, NEGORO S, OKAMOTO I et al. Gefitinib versus cisplatin plus docetaxel in patients with non-small-cell lung cancer harbouring mutations of the epidermal growth factor receptor (WJTOG3405): an open label, randomised phase 3 trial. Lancet Oncol 2010; 11: 121-128. https:/doi.org/10.1016/S1470-2045(09)70364-X

[50] OZYALVACLI G, YASAR Z. Is MPV a real prognostic indicator for non-small cell lung cancer? Asian Pac J Cancer Prev 2014; 15: 8003. https:/doi.org/10.7314/APJCP.2014.15.18.8003 